\title{
Evaluación y diagnóstico de las dificultades de aprendizje de la lectura y ortografía en Educación Primaria
}

\section{Evaluation and diagnosis of reading and spelling learning difficulties in primary education.}

DOI: $10.46932 / \operatorname{sjdv2n2-138}$

Received in: March 1st, 2021

Accepted in: May 30th, 2021

\author{
Juani González Muñoz \\ Graduated as an elementaryschool teacher, \\ Institution: RG Formación \\ Calle Rosalía de Castro, 44, 30107 Murcia \\ Belén Cánovas Calderón \\ Graduated as an elementaryschool teacher, \\ Institution: RG Formación \\ Calle Rosalía de Castro, 44, 30107 Murcia

\section{Rocío Muñoz Melgar} \\ Graduated as an elementaryschool teacher, \\ Institution: RG Formación \\ Calle Rosalía de Castro, 44, 30107 Murcia \\ Jose María Rabal Alonso \\ Professor ISEN Centro Universitario \\ Institution: Universidad de Murcia \\ Calle Campus Universitario, 12, 30100 Murcia \\ E-mail: josemaria.rabal@um.es
}

\section{RESUMEN}

En este trabajo se va a tratar de explicar, en primer lugar, la evaluación de las dificultades de aprendizaje de la lectura. Destacaremos aquellas señales que nos indican que los alumnos necesitan ayudas educativas ordinarias, y cuáles son los instrumentos que nos ayudan a identificarlas. En segundo lugar hablaremos de la evaluación de las dificultades de aprendizaje de la lectura, diferenciando entre las principales limitaciones que presentan los alumnos con dificultades de aprendizaje de la escritura (en adelante DAE) y las fases por las que este tipo de alumnado pasa. En último lugar, hablaremos tanto de la tarea de diagnóstico, las herramientas de evaluación y de la formulación de los informes.

Como docentes tenemos la obligación de estar atentos a la diversidad de nuestro alumnado. Hoy en día tenemos numerosos recursos a nuestra disposición para poder identificar cuáles son sus dificultades, y poder ofrecerles un apoyo educativo oportuno. Además añadir que es fundamental seguir formándonos y estar al día sobre los nuevos recursos, test y en general dificultades que pueden tener nuestro alumnado en el aula, con el objetivo de que consigan obtener un aprendizaje significativo.

Palabras clave: inclusión, necesidades educativas, dislexia, aprendizaje lecto-escritura, educación primaria 


\begin{abstract}
In this paper we will try to explain, first of all, the evaluation of learning difficulties in reading. We will highlight those signs that indicate that students need ordinary educational aids, and which are the instruments that help us to identify them. Secondly, we will discuss the assessment of learning difficulties in reading, differentiating between the main limitations of students with learning difficulties in writing (hereinafter DAE) and the stages through which this type of student goes through. Finally, we will discuss the diagnostic task, the assessment tools and the formulation of reports.

As teachers, we have the obligation to be attentive to the diversity of our students. Nowadays we have numerous resources at our disposal to identify their difficulties and offer them appropriate educational support. In addition, it is essential to continue training and to be updated on new resources, tests and, in general, difficulties that our students may have in the classroom, in order to achieve meaningful learning.
\end{abstract}

Key words: inclusion, educational needs, dyslexia, literacy learning, primary education.

\title{
1 EVALUACIÓN DE LAS DIFICULTADES DE APRENDIZAJE DE LA LECTURA.
}

La evaluación se implementa cuando ya hay indicios de dificultades con repercusiones negativas en la asimilación de nuevos conocimientos, y otras tareas que requieren comprensión de textos.

Se debe controlar el efecto de factores que también pudieran explicar las DAL:

- La historia clínica, socio-familiar y educativa del lector.

- El rendimiento en otros aprendizajes.

- Las estrategias emprendidas.

- Los resultados logrados.

Las primeras señales de alerta se detectan en el aula al inicio del proceso de aprendizaje de la lectura y escritura a pesar de recibir todas las ayudas educativas ordinarias

- Confundir palabras que suenan parecido (recibir/rescindir).

- Fallos al inicio de la lectura de la palabra.

- Dificultades al pronunciar la palabra que se dice leída. Lectura lenta e imprecisa.

- Error de deletreo de la palabra (casa/c-a-s-a). Dificultad en la escritura de la palabra.

- Escasa habilidad para aprender una lengua extranjera.

- Concurrencia de problemas atencionales.

- Normal comprensión oral y capacidad de razonamiento.

Para poder realizar una identificación de las dificultades específicas de aprendizaje de la lectura, estimando el grado de retraso, podemos utilizar una prueba estandarizada con la que se pueda comparar la puntuación individual con la esperada: La prueba TECLE, Carrillo Gallego, M. S., Alegría Iscoa, J., Miranda López, P., \& Sánchez Pérez, N. (2011), permite obtener puntuaciones individuales comparadas con su grupo de edad y de nivel lector en diversas pruebas: Test de eficiencia lectora: 64 frases incompletas en las que falta la última palabra, a elegir entre 4 opciones ( 2 palabras y dos pseudopalabras) de ortografía 
similar. Se puntúan los aciertos conseguidos en 5 minutos y se descuenta un tercio de los errores: $\mathrm{P}=\mathrm{A}$ $(\mathrm{E} / 3)$.

Mi amigo va en:

*bicho *bini *bidi *bici

En la siguiente fase se trata de analizar las dificultades detectadas para responder a la pregunta: ¿qué representaciones y procesos de reconocimiento de la lectura de palabras escritas están afectados?:

La prueba DIS-ESP (Carrillo y Alegría, 2011), permite evaluar los mecanismos fonológico y ortográfico de identificación de palabras. Las frecuentes y más cortas se leen mejor y más rápido, ya sean palabras o pseudopalabras:

- Lectura de palabras: 36 palabras familiares de distinta longitud (brazo, estrella, cumpleaños).

- Lectura de pseudopalabras: 36 pseudopalabras formadas combinando las sílabas de la lista de palabras /bratos/.

- Dictado de palabras: 60 palabras familiares dictadas al final de una frase, con algún grafema inconsistente $(\mathrm{b} / \mathrm{v} ; \mathrm{g}(\mathrm{e}-\mathrm{i}) / \mathrm{j}(\mathrm{e}-\mathrm{i}) ; \mathrm{h} / \varnothing$, en posición inicial (jinete) o intermedia (viaje). Decisión ortográfica: Elegir la palabra de ortografía correcta entre una palabra familiar (avión) y una pseudohomófona (abión) (66 pares)

En la última fase realizar una evaluación profesional de los componentes cognitivos de la lectura que funcionan de manera deficiente, para responder a la pregunta: ¿tienen las dificultades detectadas una causa fonológica?

La prueba DIS-ESP (Carrillo y Alegría, 2009), permite concretar los problemas en la identificación de palabras a partir de los errores fonológicos en diversas tareas cognitivas:

- Discriminación de pares mínimos: perceptiva (elaboración de representaciones fonológicas: 49 ítems con pares de sílabas "PA/BA").

- Evaluación de la fluidez verbal: representación y producción (del acceso a la representación a la producción: decir en 30 seg. El mayor número de palabras según criterio semántico o fonémico).

- Denominación rápida de imágenes: ídem (nombrar los 18 dibujos en cada uno de los 6 paneles de imágenes).

- Evaluación de la memoria fonológica: representacional (almacenamiento de representaciones fonológicas: repeticiones de 30 ítems de 1 a 5 sílabas "FE-PA-NI").

- Tarea de supresión silábica: metafonológica (análisis consciente de la estructura fonológica: suprimir una sílaba de una pseudopalabra trisilábica).

- Tarea de identificación de fonemas: ídem (identificar un fonema dado en sílabas, en distintas posiciones). 
- Tarea de supresión fonémica: ídem (suprimir ídem).

Para llevar a cabo una evaluación de las habilidades de comprensión lectora identificando las dificultades específicas de comprensión del texto debemos prestar atención en:

- No conoce el significado de algunas palabras clave.

- Pierde el hilo durante la lectura. Sabe de qué trata el texto, pero no sabe qué quieren decir con él.

- Sabe de qué habla el texto, pero no llega a interrelacionar las ideas. No sabe qué se supone que debe conocer sobre el texto.

- No sabe si ha comprendido o no lo que ha leído.

- La lectura en voz alta con corrección, fluidez y entonada indica el dominio de las habilidades de reconocimiento de palabras, mientras se presta atención a la puntuación y se accede al contenido semántico de lo que se lee.

Para una exploración específica individualizada de las dificultades detectadas:

- Concepción de la lectura que maneja el lector y sus ideas previas sobre qué es importante al leer y cuál es el propósito con el que se realiza. Conocimiento del vocabulario que se utiliza en los textos adecuados a la edad del lector.

- Identificación y extracción del significado y la relación semántica de las oraciones expresadas en el texto.

- Habilidades evolutivas para: Identificar el tema del texto, resolver expresiones anafóricas y referenciales.

- Seguir el hilo argumental.

- Conocimiento y uso de estrategias para identificar las ideas importantes.

- Conocimiento y uso estratégico de los diferentes tipos de estructuras textuales, tanto en textos continuos (narración, descripción, argumentación...), como en los discontinuos (anuncios, comics, gráficos...).

- Inferencias del lector a partir del modelo de la situación del texto intercalando preguntas a lo largo del texto, cuya respuesta esté implícita.

- Integración de información textual y conocimientos previos a partir de informaciones obtenidas por varias fuentes (textos, dibujos, gráficos...) y reelaborar los contenidos con los conocimientos previos que posee el lector sobre el mismo tema.

- Capacidad para entender la intención comunicativa del autor: preguntar directamente al lector qué pretende comunicar el autor y que argumente su respuesta.

- Conocimiento y control metacognitivo de la comprensión a distintos niveles: Observar y registrar si el lector corrige espontáneamente los errores de naturaleza semántica que comete durante la 
lectura, y comprobar si el lector tiene estrategias de detección posibles inconsistencias semánticas en el texto: relectura, comparar con lo que sabe...

Qué estrategias de resolución de problemas usa el lector. Solicitar la evaluación del lector acerca del grado de dificultad del texto y sobre el grado en que lo ha comprendido. Para realizar una evaluación de proceso y producto mediante pruebas estandarizadas podemos utilizar la Batería de Evaluación de los Procesos Lectores-revisada (ProlecR) (Cueto y otros, 2014) que evalúa los procesos cognitivos de lectores en Educación Primaria.

\section{EVALUACIÓN DE LAS DIFICULTADES DE APRENDIZAJE DE LA ESCRITURA.}

En primer lugar, debemos conocer la importancia de la implicación de todos los agentes educativos, tanto para la evaluación como para la intervención. La detección se hace sobre alumnos que, recibiendo las mismas ayudas que los demás, no progresan en su aprendizaje escritor. Antes de la evaluación debemos realizar el descarte de factores no evolutivos que puedan justificar los problemas de AE.

La interrelación entre DAL y DAE justifica la exploración de las dificultades que se puedan presentar en el otro aspecto. Una alerta en escritura debe servir para evaluar también la lectura y corresponde al profesorado tutor la detección y derivación a especialistas de los alumnos que presentan rasgos llamativos en sus redacciones, copias, dictados, etc. Las principales limitaciones presentes en los alumnos con DAE son:

\section{- ERRORES GENERALES:}

Menor habilidad en los procesos de ejecución de la escritura, desestructuración textual (contenido lineal) y expresión del contenido de forma confusa e incoherente. Necesitan mayor tiempo para la tarea, desconfían de su aprendizaje y experimentan el sentimiento de fracaso. En consecuencia, acaban mostrando desmotivación hacia el aprendizaje instrumental de la escritura. Se les puede identificar por sus problemas de comportamiento y/o reacciones neuróticas, consecuencia de su frustración escolar.

\section{- ERRORES ESPECÍFICOS:}

Errores mecánicos: los alumnos con DAE, en relación con el resto de alumnos de su curso, cometen más errores de ortografía, utilizando azarosamente las mayúsculas, así como los signos de puntuación. También el grafismo es más ilegible, produciendo textos con estructura gráfica desorganizada (líneas anómalas, oscilantes, interlineado desigual, soldadura de letras, tamaño irregular de letras dentro de la misma palabra...).

Escasa productividad en sus composiciones de textos: generalmente escriben textos cortos, incompletos, con datos superfluos, incoherentes y faltos de organización. Todo ello parece deberse a la falta de planificación y la ausencia de una estructura previa de ideas que reflejar en el texto. La actitud de 
rechazo hacia la tarea y sus frecuentes protestas desembocan en una producción escrita cada vez más limitada, mientras sus iguales automatizan la escritura y aprovechan la eficiencia en el empleo de recursos para ampliar los textos y enriquecer sus estructuras. Escaso uso de los procesos de autorregulación: demuestran menos conciencia y control metacognitivo, de manera que no realizan adecuadamente los procesos de planificación, supervisión, evaluación y revisión de sus escritos. Centran su percepción interna en aspectos concretos de la tarea escritora (deletreo, ideas fragmentarias), en detrimento de los aspectos más abstractos como los aspectos retóricos, las necesidades del futuro lector, la generación de una macroestructura apropiada para contextualizar las ideas dentro de los límites del tema... Revisión ineficaz: cuando a estos alumnos con DAE se les propone revisar su propia producción textual, se comprueba su ineficiencia de cara a la mejora cualitativa de la composición escrita. Se limitan a sustituir palabras, corregir errores mecánicos y presentar un escrito más limpio, sin prestar atención a las necesidades del lector. Están centrados en su propia tarea mecánica y no activan habilidades de revisión metacognitivas.

Actitud negativa: los alumnos con DAE tienen un conocimiento inmaduro sobre lo que representa el texto como producto escrito, de manera que sobrevaloran sus propios trabajos y se presentan poco positivos hacia las revisiones o las críticas de sus padres y/o profesores. La actitud negativa perjudica la posibilidad de mejora, ya que no practican la escritura con agrado y no alcanzan niveles de automatización que se traduzca en mayor eficiencia en su producción.

Las fases en la evaluación de las DAE son:

\section{- FASE DE IDENTIFICACIÓN}

Identificación de alumnos con posibles DAE con pruebas estandarizadas, diferenciándolos de aquellos que no presentan dificultades y también de los que únicamente muestran un retraso en la adquisición. Las pruebas estandarizadas disponibles proporcionan fundamentalmente información sobre el grado de dificultad que presenta el sujeto respecto a su grupo normativo, pero requieren un análisis interpretativo posterior por parte de expertos y complementarse con otras pruebas que muestren qué procesos están afectados, para centrar la intervención rehabilitadora sobre ellos.

Desde $1^{\circ}$ de Primaria se viene utilizando el Test de Análisis de la Lectura y la Escritura (TALE), de Cervera y Toro (1980). A partir de $3^{\circ}$ de primaria la Batería de Evaluación de los Procesos de Escritura (PROESC) de Cuetos, Ramos y Ruano (2002) permite el análisis de los procesos básicos léxicos y sintácticos, así como de los procesos complejos.

\section{- FASE DE EVALUACIÓN DE PROCESOS}

Es recomendable complementar las pruebas estandarizadas con tareas orientadas al análisis específico y concreto de los procesos que se muestran deficitarios. La determinación con pruebas no 
estandarizadas, de los procesos o habilidades que limitan y dificultan el aprendizaje de la escritura: Limitaciones que atañen a los procesos básicos de escritura léxicos. Limitaciones que atañen a los procesos básicos de escritura sintácticos. Dificultades en los procesos complejos de composición de textos. Cuestiones periféricas relacionadas con la motricidad.

\subsection{FASES EN LA EVALUACIÓN DE LAS DAE:}

- PRIMERA FASE:

Evaluación de los procesos básicos lingüísticos léxicos, para la determinación de la Disortografía Natural (Disgrafía Central Fonológica), la Disortografía Arbitraria (Disgrafía Central Superficial), y la Disgrafía Central Profunda o Mixta. Se debe comenzar por la exploración de la conciencia fonológica: segmentación fonémica y silábica (dictado de fonemas, de palabras, de pseudopalabras, juegos de rimas y de integración de sílabas aisladas para construir palabras. A continuación explorar el Lexicón semántico mediante la denominación escrita de imágenes (presentar láminas). Por último, explorar las vías de acceso al léxico mediante el dictado de palabras (de ortografía natural, sub-léxica, fonológica: “casa” y pseudopalabras: "saplo"; de ortografía arbitraria, léxica, directa: “prohibir").

\section{- SEGUNDA FASE}

Evaluación de los procesos básicos lingüísticos sintácticos, que permiten la construcción de las proposiciones y su coordinación para formar la microestructura del texto. Se deben registrar el tipo de oraciones, su complejidad sintáctica, longitud y el uso de signos de puntuación (reescritura de textos mediante frases cortas, completar el contenido de estructuras, reorganizar frases incoherentes, generar frases a partir de imágenes, y textos mediante láminas de cuentos o historias). Merece atención especial la medida de la MLP (Memoria Largo Plazo) mediante tests específicos (Batería TOMAL de Goikoechea, 2011), y de la MO (Memoria Operativa)(Reading Span Test, adaptado por Elosúa y otros, 1997).

\section{- TERCERA FASE}

Evaluación de los procesos complejos de producción de textos a través del análisis de las estrategias que emplean los sujetos. Se lleva a cabo una indagación previa sobre los conocimientos previos del escritor frente a la tarea de redacción productiva de un texto (planificación, generación de ideas y revisión final), para luego observar directamente cómo realiza la ejecución de su escrito. Una vez producido el texto identificar la microestructura de ideas, su jerarquización dentro de la macroestructura, y la superestructura en función del género textual de la redacción (descriptivo, narrativo, argumentativo...), y además evaluar el empleo de conectores dentro del texto.

\section{- CUARTA FASE}

Evaluación de los procesos motóricos a partir de los materiales recogidos durante los procesos anteriormente realizados. Así se puede evaluar la "caligrafía", la organización global del texto, la 
linealidad y la claridad del escrito, ya sea de dictados o redacciones. Como la adquisición instrumental de la escritura no se automatiza antes de los 7-8 años, no se puede diagnosticar inicialmente una Disgrafía Periférica Motórica. Es necesario diferenciar, mientras tanto, problemas de coordinación óculo-motriz, prensión de la "pinza escribana", irregularidad del trazo, inclinación de líneas, ausencia de márgenes o amontonamiento del texto en alguna parte de la hoja. Podría pensarse actualmente que el uso de teclados electrónicos para escribir resta importancia al aprendizaje de la caligrafía, sin embargo, la automatización de los patrones motóricos es esencial para liberar espacio en la MO que debe quedar a disposición de otros procesos más complejos y abstractos requeridos para llevar a cabo la tarea escrita

En las siguientes tablas encontraremos unas plantillas de evaluación cualitativa. Dependiendo de los diferentes procesos se han creado unos ítems u otros.

\subsection{PROCESOS COMPLEJOS DE CARÁCTER COGNITIVO Y REPRESENTACIONAL:}

\begin{tabular}{|l|l|l|l|}
\hline ÍTEM & SÍ & NO & OBSERVACIONES \\
\hline RESPETO DE LOS & & & \\
MÁRGENES EN LA & & & \\
PRODUCCIÓN DEL & & & \\
TEXTO & & \\
\hline AUSENCIA DE & & & \\
ESPACIOS ENTRE & & & \\
PALABRAS & & \\
\hline PRESENTA UNA & & & \\
COHERENCIA CON & & & \\
EL ORDEN DE & & & \\
CONTENIDOS & & & \\
\hline EL TEXTO & & & \\
CONTIENE & & & \\
SUPERESTRUCTURA & & & \\
USO CORRECTOS DE & & & \\
DEL TEXTECTORES & & & \\
\hline
\end{tabular}

2.4 PROCESOS BÁSICOS DE CRÁCTER LINGÜISTICO: LÉXICO

\begin{tabular}{|l|l|l|l|}
\hline ÍTEM & SÍ & NO & OBSERVACIONES \\
\hline ERRORES DE & & & \\
ACENTUACIÓN & & & \\
\hline ADICIONES DE & & & \\
PALABRAS & & & \\
\hline OMISIONES DE & & & \\
PALABRAS & & & \\
\hline CONFUSIÓN DE & & & \\
MAYÚSCULAS Y & & & \\
MINÚSCULAS & & & \\
\hline
\end{tabular}




\begin{tabular}{|l|l|l|l|}
\hline SUSTITUCIÓN DE & & & \\
PALABRAS & & & \\
\hline PRODUCCIÓN DE & & & \\
PSEUDOPALABRAS & & & \\
\hline UNIÓN DE & & & \\
PALABRAS & & & \\
CONFUSIÓN DE LAS & & & \\
\hline CONFUSAS (P/Q O B/D) & & & \\
GRAFEMAS DE POR SU & & & \\
FORMA & & & \\
\hline FRAGMENTACIÓN & & & \\
DE PALABRAS & & & \\
\hline
\end{tabular}

2.5 PROCESOS BÁSICOS DE CARÁCTER LINGÜISTICOS: SINTAXIS

\begin{tabular}{|c|c|c|c|}
\hline ITÉM & Sí & $\mathrm{NO}$ & OBSERVACIONES \\
\hline $\begin{array}{l}\text { SENTIDO LÓGICO } \\
\text { DEL TEXTO }\end{array}$ & & & \\
\hline $\begin{array}{l}\text { CONCORDANCIA } \\
\text { ENTRE EL VERBO } \\
\text { Y EL SUJETO } \\
\text { CONCORDANCIA } \\
\text { ENTRE SUJETO Y } \\
\text { NÚMERO }\end{array}$ & & & \\
\hline $\begin{array}{l}\text { CONCORDANCIA } \\
\text { ENTRE VERBO Y } \\
\text { SINTAGMAS }\end{array}$ & & & \\
\hline $\begin{array}{l}\text { REALIZA FRASES } \\
\text { CORRECTAMENTE } \\
\text { ESTRUCTURADAS }\end{array}$ & & & \\
\hline $\begin{array}{l}\text { CONCORDANCIA } \\
\text { ENTRE SUJETO Y } \\
\text { GÉNERO }\end{array}$ & & & \\
\hline $\begin{array}{l}\text { USO DE SIGNOS } \\
\text { DE PUNTUACIÓN }\end{array}$ & & & \\
\hline
\end{tabular}

2.6 PROCESO PSICOMOTÓRICOS DE COORDINACIÓN VISIOMOTORA

\begin{tabular}{|l|l|l|l|}
\hline ÍTEM & SÍ & NO & OBSERVACIONES \\
\hline LÍNEAS ANÓMALAS & & & \\
\hline CLARIDAD & & & \\
CALIGRÁFICA & & & \\
\hline REGULARIDAD EN & & & \\
LA ESCRITURA & & & \\
\hline
\end{tabular}




\begin{tabular}{|l|l|l|l|}
\hline TRAZO TENSO DE & & & \\
LA ESCRITURA & & & \\
\hline TAMAÑO & & & \\
IRREGULAR DE LAS & & & \\
LETRAS & & \\
\hline
\end{tabular}

\section{HERRAMIENTAS DE EVALUACIÓN Y FORMULACIÓN DEL INFORME.}

Como toda evaluación psicopedagógica, la tarea de diagnóstico implica a psicólogos, pedagogos, logopedas y profesores especialistas en dificultades de aprendizaje y/o audición y lenguaje. Conviene disponer de un modelo teórico que incluya una metodología, instrumentos, materiales y técnicas que den respuesta al modelo en que se fundamentan de lo que emanará un modelo de informe que integrará las conclusiones explicativas y las orientaciones dentro de unas propuestas de intervención coherentes con la teoría. Los informes deben ser replicables al evidenciar información cualitativa y cuantitativa, y estar dirigidos hacia funciones o destinatarios concretos. Es responsabilidad de los profesionales implicados atender a las disposiciones normativas para garantizar los derechos de los alumnos (Resolución de 30 de julio de 2019, de la Dirección General de Atención a la Diversidad y Calidad Educativa por la que se dictan instrucciones para la identificación y la respuesta educativa a las necesidades del alumnado que presenta dificultades de aprendizaje). Podemos encontrar diferentes tipos de herramientas:

- 1. BECOLE

La Batería de Evaluación Cognitiva de la Lectura y la escritura, de Galve (2005), EOS se puede realizar desde $3^{\circ}$ de Primaria a $1^{\circ}$ de ESO. Valora diferentes aspectos como:

- Los procesos de desarrollo de la lectura (comprensión) y de la escritura (producción)

- El nivel lingüístico a través del funcionamiento de las rutas de acceso al léxico

- El funcionamiento de los niveles de procesamiento léxico, sintáctico-semántico, a nivel oracional, en la lectura y en la escritura

De esta prueba deriva el Programa Becoleando (EOS), para intervenir a nivel de procesos, de componentes, de tareas y de errores, con 12 cuadernos para dislexia/disgrafía.

\section{- 2. PROLEC-R}

Es la evaluación de los Procesos Lectores en niños de Educación Primaria de Cuetos y otros (2007), TEA. Se realiza desde $1^{\circ}$ hasta $6^{\circ}$ de Primaria. Valora diferentes aspectos como:

- Los niveles de desarrollo de la lectura.

- Los niveles de comprensión.

- El nivel lingüístico a través de las rutas implicadas en estos procesos.

- El funcionamiento de los niveles de procesamiento léxico, sintáctico y semántico de la lectura. 
Es la evaluación de los Procesos de Escritura, de Cuentos y otros (2002), TEA. Se realiza desde los 8 hasta los 15 años. Valora diferentes aspectos como:

- El funcionamiento de los niveles de procesamiento léxico, sintáctico y semántico de la escritura.

- El nivel lingüístico a través de las rutas implicadas en estos procesos.

\section{- 4. ECLE 1-2}

Es la Evaluación de la Comprensión Lectora, de Galve y otros (2010), EOS. Se lleva a cabo desde $2^{\circ}$ hasta $6^{\circ}$ de Primaria. Valora el rendimiento en comprensión lectora y aspectos complementarios como:

- Estrategias con textos narrativos y expositivos.

- Vocabulario.

- Fluidez/velocidad lectora.

- Precisión en la lectura de palabras.

- Tiempo empleado.

\section{- 5. EMLE-TALE 2000}

Son las Escalas Magallanes de Lectura y Escritura, de Toro y Cervera, ALBOR-COHS. Se desarrolla desde $1^{\circ}$ de primaria hasta $4^{\circ}$ de ESO. (Nueva versión del Test de Análisis de la LectoEscritura). El objetivo de la evaluación mediante la EMLE es identificar el nivel de destreza alcanzado por un niño en la lectura en voz alta, su nivel de comprensión, sus habilidades caligráficas, además de detectar deficiencias específicas tanto en lectura como en escritura. La intervención irá encaminada a la superación de los déficit detectados, sentando las bases para el diseño de un Programa de Intervención para mejorar la destreza en lectura y escritura, ajustado a las habilidades de lectura en voz alta, comprensión lectora, copia y dictado mostrados por el niño. Con la experiencia de su empleo en diagnóstico durante más de veinte años, los autores presentan una versión muy diferente, especialmente en lo que hace referencia a la evaluación de la Comprensión Lectora. El software de corrección permite obtener un Informe Individual de resultados de cada niño.

Lectura en Voz Alta.

Conversión grafema-fonema

Forma A: $1^{\circ}$ y $2^{\circ}$ de Primaria

Forma B: $3^{\circ}$ de Primaria en adelante

Fluidez Lectora

Texto 1: $1^{\mathrm{o}}$ y $2^{\mathrm{o}}$ de Primaria

Texto $2: 3^{\circ}, 4^{\circ}$ y $5^{\circ}$ de Primaria 
Texto 3: $6^{\circ}$ de Primaria en adelante

Comprensión lectora.

Texto 1: $2^{\circ}$ y $3^{\circ}$ de Primaria

Texto $2: 4^{\circ}, 5^{\circ}$ y $6^{\circ}$ de Primaria

Texto 3: $1^{\circ}, 2^{\circ}, 3^{\circ}$ y $4^{\circ}$ de E.S.O.

\section{Dictado y Copia}

En función del curso y del nivel alcanzado en lectura.

\section{- 6. PRO 1-2}

Es la Evaluación del Rendimiento Ortográfico, de Galve y otros (2010), CEPE

PRO 1 para $3^{\circ}$ y $4^{\circ}$ de Primaria.

PRO 2 para $5^{\circ}$ y $6^{\circ}$ de Primaria.

Constituye una valoración integral del rendimiento ortográfico en función de los niveles de procesamiento léxico, sintáctico y semántico: Dominio de las normas de la ortografía reglada y arbitraria, así como de las normas de acentuación. Valoración de los procesos sintácticos a través de la utilización de signos de puntuación. Valoración de los procesos semánticos a través del uso de homófonos en su contexto (con dictados que incluyen ambas posibilidades homófonas el niño deberá escribir el ortográficamente correcto: a-ha, arrollo-arroyo). De esta prueba emana el Programa Ortoleco (CEPE), para la intervención sobre el aprendizaje de la ortografía, con 12 cuadernos.

\section{- 7. ROGLA}

Es el Registro de Observación de la Grafía, de Galve. Se utiliza para valorar la grafía a cualquier edad y curso escolar. Evalúa cualitativamente los dos aspectos que intervienen en el proceso grafo-motriz:

- La posición relativa de los elementos biomecánicos escritores (posición y pinza).

- La propia producción escrita (grafismo

\section{- 8. RECUTE}

Es el Registro de Evaluación Cualitativa de Textos Escritos, de Galve. Se utiliza para valorar la producción escrita a cualquier edad y curso escolar. Dependiendo del nivel de instrumentalización del alumno se le puede pedir la producción de una descripción, narración, redacción y/o cuento. Durante la elaboración de evaluador deberá anotar observaciones directas y continuas. 
Debemos valorar alteraciones asociadas con las DA de la lectoescritura, tales como: Mala lateralización: los estudios muestran que la lateralidad cruzada (ojo-mano) o la zurdería de la mirada dan mayor porcentaje de problemas de aprendizaje.

Alteraciones de Psicomotricidad: inmadurez motora, torpeza, hipo o hipertonía, falta del sentido del ritmo, respiración irregular, desequilibrio dinámico y falta de integración del esquema corporal.

Problemas Perceptivos: la desorientación respecto a los ejes de referencia en la capacidad de codificación de signos gráficos y su estructuración en secuencias. Alteraciones de Lenguaje: se presentan problemas por alteraciones verbales y de ritmo, caracterizadas por dislalias, pobreza de expresión, de fluidez para hablar o baja comprensión de las reglas sintácticas.

\section{REDACCIÓN DEL INFORME DE EVALUACIÓN}

El modelo de informe debe adaptarse a la finalidad y al destinatario del mismo. Para el profesorado especialista en DA un modelo de informe puede basarse en la plantilla utilizada por los equipos de orientación. Las pruebas y sus resultados serán en cada caso las utilizadas por el profesor dentro del aula. Los apartados fundamentales del informe son:

- Datos personales del alumno/a.

- Motivo de la evaluación.

- Técnica e instrumentos utilizados.

- Datos familiares.

- Datos médicos.

- Datos escolares.

- Niveles y datos del desarrollo (resultados de las pruebas de lecto-escritura).

- Determinación de las necesidades educativas especiales.

- Orientaciones para la propuesta curricular (apoyos y adaptaciones de acceso y/o curriculares.

- Propuesta de seguimiento 


\section{REFERENCIA}

Carrillo Gallego, M. S., Alegría Iscoa, J., Miranda López, P., \& Sánchez Pérez, N. (2011). Evaluación de la dislexia en la escuela primaria: Prevalencia en español. Escritos de Psicología (Internet), 4(2), 35-44.

Carrillo Gallego, M. S., Alegría Iscoa, J., Miranda López, P., \& Sánchez Pérez, N. (2011). Evaluación de la dislexia en la escuela primaria: Prevalencia en español. Escritos de Psicología (Internet), 4(2), 35-44.

González-Trujillo, M. C., Calet, N., Defior, S., \& Gutiérrez-Palma, N. (2014). Scale of readingfluency in Spanish: measuringthecomponents of fluency/Escala de fluidez lectora en español: midiendo los componentes de la fluidez. Estudios de Psicología, 35(1), 104-136.

Cervera, M., Toro, J., \& Pablo del Río. (1980). Test de Análisis de la Lectura y la Escritura. Madrid.

Cuetos, F., Ramos, J. L., \& Ruano, E. (2002). PROESC. Evaluación de los procesos de escritura. Madrid: TEA.

Goicochea, Z. I. N. (2011). Valoración económica del patrimonio natural: las áreas naturales protegidas. Espacio y Desarrollo, (23), 131-154.

Elosúa, M. R., Madruga, J. A. G., Gutiérrez, F., Luque, J. L., \& Garate, M. (1997). Un estudio sobre las diferencias evolutivas en la memoria operativa:¿ Capacidad o eficiencia?. Estudios de psicología, 18(58), $15-27$.

Galve, J. L. (2005). BECOLE. Batería de evaluación cognitiva de la lectura y la escritura.

Cuetos, F., Rodríguez, B., Ruano, E., \& Arribas, D. (2007). Prolec-r. Evaluación de los procesos lectoresrevisado. Madrid: TEA.

Abregú, L., Alcántara, M., Dioses, A., Galve, J., \& Ramos, J. (2010). ECLE: Prueba de evaluación de las competencias de comprensión lectora. Madrid: Eos.

Galve Manzano, J. L. (2010). Intervención psicoeducativa en el aula con TDAH. EducationalPsychology, 15(2), 87-106. 
ANEXO 1:

Ilustración 1: ANA 6 AÑOS

Ilustración 2: ANA 7 AÑOS

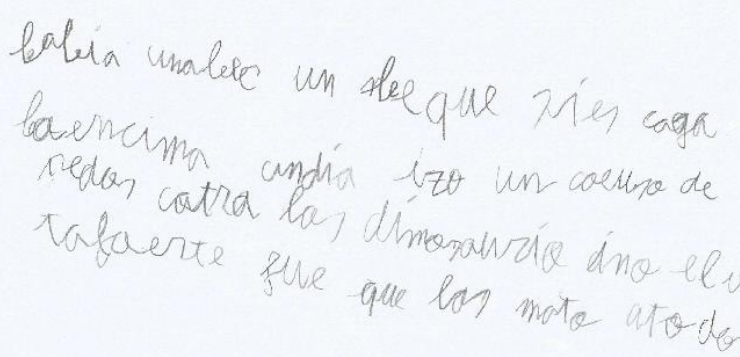




\section{Ilustración 3: ANA 9 AÑOS}

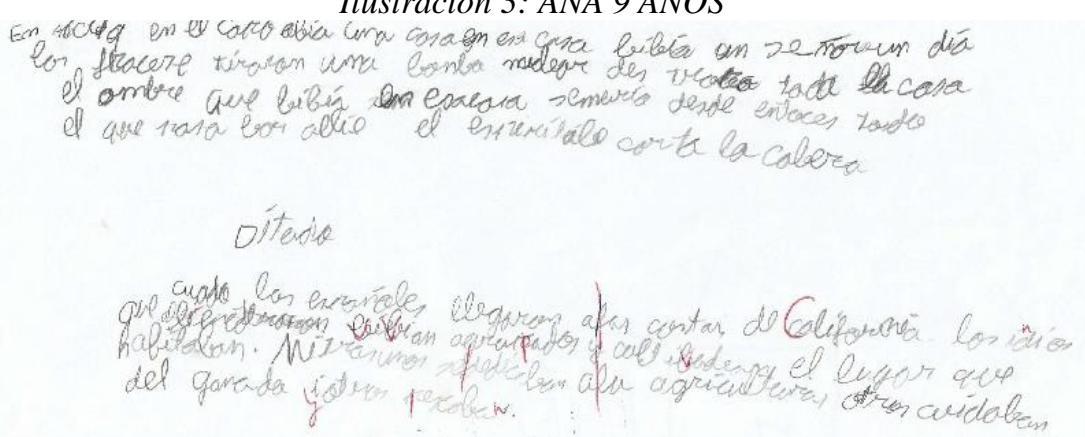

Ilustración 4: ANA 11 AÑOS

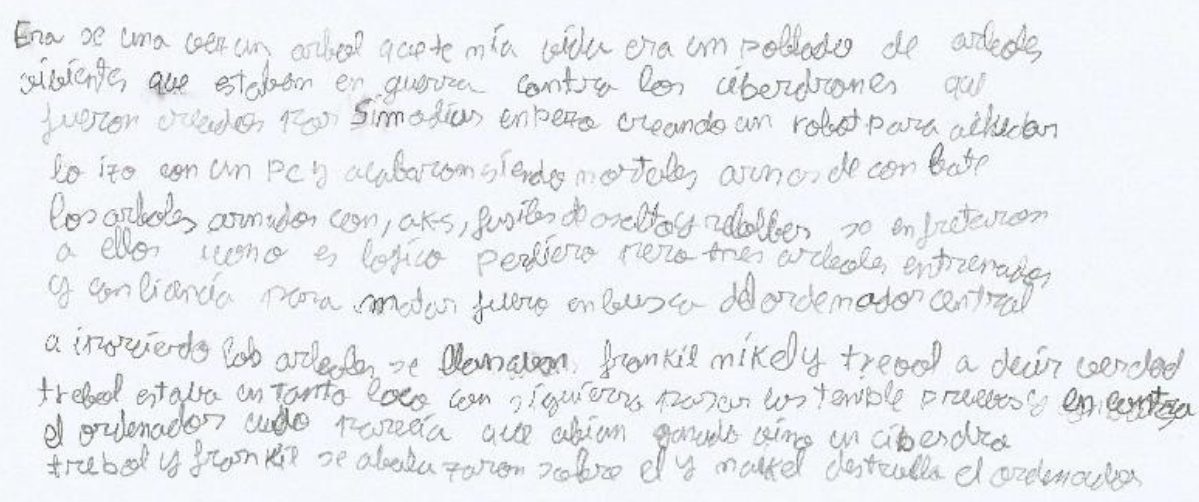

jin

\begin{tabular}{|l|l|l|}
\hline & 6 AÑOS & 7 AÑOS \\
\hline $\begin{array}{l}\text { Procesos complejos de carácter } \\
\text { cognitivo y representacional }\end{array}$ & $\begin{array}{l}\text { No existe una coherencia entre el } \\
\text { orden de los contenidos del texto } \\
\text { ni hay uso de conectores, ni } \\
\text { espacios entre palabras debido a } \\
\text { que el texto está formado por una } \\
\text { sola palabra. }\end{array}$ & $\begin{array}{l}\text { No presenta ausencia de espacio } \\
\text { entre palabras. No existe } \\
\text { coherencia ya que el texto no } \\
\text { sigue una idea principal sino que } \\
\text { varía. Ya hace uso de conectores } \\
\text { en el texto. }\end{array}$ \\
\hline $\begin{array}{l}\text { Procesos básicos de carácter } \\
\text { lingüístico: léxico }\end{array}$ & $\begin{array}{l}\text { La palabra escrita se puede } \\
\text { escribir acentuada o no por lo } \\
\text { que, al no saber el contexto de la }\end{array}$ & $\begin{array}{l}\text { Presenta errores de acentuación } \\
\text { debido a que acentúa todas las } \\
\text { palabras con "i". Realiza }\end{array}$ \\
\hline
\end{tabular}




\begin{tabular}{|c|c|c|}
\hline & $\begin{array}{l}\text { palabra, no podemos saber si hay } \\
\text { error ortográfico. No presenta } \\
\text { omisiones, sustituciones, } \\
\text { adiciones, producción de } \\
\text { pseudopalabras, fragmentación } \\
\text { ni unión de palabras al estar el } \\
\text { texto formado por una sola } \\
\text { palabra. Tampoco confunde las } \\
\text { grafías ni grafemas por su forma. } \\
\text { Sin embargo, observamos que no } \\
\text { respeta los márgenes en la } \\
\text { producción ya que se observa que } \\
\text { el texto se escribe en unpapel } \\
\text { horizontal en lugar del vertical. }\end{array}$ & $\begin{array}{l}\text { omisiones, por ejemplo al } \\
\text { principio del texto pone: "un be } \\
\text { que" está omitiendo una palabra } \\
\text { al poner el "be", la cual no } \\
\text { sabemos cual es. También une } \\
\text { palabras, por ejemplo une las } \\
\text { palabras "una" y "bez". Del } \\
\text { mismo modo, respeta los } \\
\text { márgenes a la hora de comenzar a } \\
\text { escribir. Por otro lado, no } \\
\text { produce adiciones, producción de } \\
\text { pseudopalabras, } \\
\text { sustituciónfragmentaciones ni } \\
\text { confusión de grafías ni grafemas } \\
\text { por su fonema }\end{array}$ \\
\hline $\begin{array}{l}\text { Procesos básicos de carácter } \\
\text { lingüístico: sintaxis }\end{array}$ & $\begin{array}{l}\text { El texto no tiene sentido lógico, } \\
\text { concordancia entre sujeto y } \\
\text { verbo, género y número, } \\
\text { concordancia entre el verbo y los } \\
\text { sintagmas, no hay un uso de los } \\
\text { signos de puntuación ni tiene } \\
\text { frases correctamente } \\
\text { estructuradas debido a que solo } \\
\text { hay una palabra. }\end{array}$ & $\begin{array}{l}\text { No presenta un sentido lógico } \\
\text { puesto que no se entiende muy } \\
\text { bien lo que hay escrito. Tampoco } \\
\text { hay concordancia entre sujeto y } \\
\text { número, por ejemplo, con "los } \\
\text { dinosaurios" ni realiza frases } \\
\text { correctamente estructuradas } \\
\text { debido a que algunas de las frases } \\
\text { que realiza no tienen ningún } \\
\text { sentido. No utiliza ni puntos, ni } \\
\text { comas, ni acentos en las palabras } \\
\text { que lo necesitan. Por otro lado, } \\
\text { presenta concordancia entre el } \\
\text { verbo con el sujeto y los } \\
\text { sintagmas y concordancia entre el } \\
\text { sujeto y el género. }\end{array}$ \\
\hline $\begin{array}{l}\text { Proceso psicomotóricos } \mathrm{de} \\
\text { coordinación visomotora }\end{array}$ & $\begin{array}{l}\text { La palabra aparece escrita } \\
\text { curvada, pero como no hay más } \\
\text { palabras no se unen las líneas. No } \\
\text { tiene claridad caligráfica debido a } \\
\text { que tanto la "e" como la "a" sé de } \\
\text { "esta" pueden llevar a confusión. } \\
\text { Se puede apreciar que aprieta } \\
\text { mucho el lápiz, y que ha repasado } \\
\text { la palabra una vez escrita. } \\
\text { Además, se muestra un tamaño } \\
\text { normal, quizás un poco más } \\
\text { grande, pero tampoco excesivo. }\end{array}$ & $\begin{array}{l}\text { No hay claridad caligráfica ya que } \\
\text { algunos casos no se entiende lo } \\
\text { que está escribiendo. En algunas } \\
\text { partes del texto escribe bien las } \\
\text { palabras y con clarisas y en otras } \\
\text { no se entiende nada por lo que no } \\
\text { presenta regularidad en la } \\
\text { escritura. No hay trazo tenso en la } \\
\text { escritura, esto se puede observar } \\
\text { cómo escribe con un trazo en su } \\
\text { mayoría regular.El tamaño de las } \\
\text { letras es más o menos el mismo } \\
\text { excepto en una o dos letras. } \\
\text { Además, el texto presenta líneas } \\
\text { anómalas. }\end{array}$ \\
\hline
\end{tabular}

\begin{tabular}{|c|c|c|}
\hline & 9 AÑOS & 11 AÑOS \\
\hline $\begin{array}{l}\text { Procesos complejos de carácter } \\
\text { cognitivo y representacional }\end{array}$ & $\begin{array}{l}\text { No deja un espacio considerable } \\
\text { para que se entienda la } \\
\text { diferenciación de las } \\
\text { palabras,hay coherencia de ideas } \\
\text { y en el primer texto no presenta } \\
\text { ningún conector }\end{array}$ & $\begin{array}{l}\text { Deja espacio entre las palabras. } \\
\text { El texto parece ser una historia, } \\
\text { contada o inventada que tieneuna } \\
\text { correcta estructuración del orden } \\
\text { de contenidos. Por último, usa los } \\
\text { conectores correctamente. }\end{array}$ \\
\hline $\begin{array}{l}\text { Procesos básicos de carácter } \\
\text { lingüístico: léxico }\end{array}$ & $\begin{array}{l}\text { Comete errores de acentuación ya } \\
\text { que parece que acentúa todas las } \\
\text { "i", realiza adiciones como "a }\end{array}$ & $\begin{array}{l}\text { Comete errores de acentuación lo } \\
\text { que provoca que el texto no se } \\
\text { logre entender enteramente, en }\end{array}$ \\
\hline
\end{tabular}




\begin{tabular}{|c|c|c|}
\hline & $\begin{array}{l}\text { las" lo ha unido creando otra } \\
\text { palabra "alas". "Se dedicaban" } \\
\text { también lo ha unido formando } \\
\text { "sededicaban". } \\
\text { palabras como "Cairo" por } \\
\text { "caro" o "A las " por "alas". } \\
\text { Además produce pseudopalabras } \\
\text { como "Feracere" "nudear" } \\
\text { "semario". Del mismo modo, une } \\
\text { palabras. En el primer texto no lo } \\
\text { podemos observar con tanta } \\
\text { claridad como en el segundo, } \\
\text { donde junta "a las ", "a la", y } \\
\text { "iotros". Confunde grafemas por } \\
\text { su fonema, por ejemplo, } \\
\text { confunde a la "b" con la "v", no } \\
\text { pone el grafema "h" debido a que } \\
\text { no suena, y cuando tiene que } \\
\text { poner " y otros" en vez de el } \\
\text { grafema "y" pone la vocal "i", ya } \\
\text { que suena de la misma manera. } \\
\text { Por otro lado, no realiza } \\
\text { omisiones, entre las palabras no } \\
\text { confunde las mayúsculas con las } \\
\text { minúsculas, no hay confusión de } \\
\text { grafías ni fragmentación de } \\
\text { palabras }\end{array}$ & $\begin{array}{l}\text { algunas líneas del texto se puede } \\
\text { observar la producción de } \\
\text { pseudopalabras y fragmentación } \\
\text { de palabras, por ejemplo, "tenía", } \\
\text { que la separa y pone "te nia" y } \\
\text { respeta los márgenes. Por otro } \\
\text { lado, no presenta adiciones, } \\
\text { omisiones, sustituciones, } \\
\text { uniones, confusión de grafías y } \\
\text { grafemas por su fonema. }\end{array}$ \\
\hline $\begin{array}{l}\text { Procesos básicos de carácter } \\
\text { lingüístico: sintaxis }\end{array}$ & $\begin{array}{l}\text { El texto presenta concordancia } \\
\text { entre el sujeto y el verbo, el verbo } \\
\text { y los sintagmas y concordancia } \\
\text { entre el sujeto y el género, } \\
\text { presenta un sentido lógico, tiene } \\
\text { concordancia entre sujeto y } \\
\text { número y las frases que realiza } \\
\text { tienen sentido ya que está } \\
\text { correctamente estructurado. Por } \\
\text { otro lado, utiliza ni puntos, } \\
\text { nicomas, ni acentos en las } \\
\text { palabras que lo necesitan por lo } \\
\text { que presenta problemas con los } \\
\text { signos de puntuación }\end{array}$ & $\begin{array}{l}\text { El texto presenta un sentido } \\
\text { lógico puesto que es una historia } \\
\text { y realiza frases correctamente } \\
\text { estructuradas. Además, tiene } \\
\text { concordancia entre el sujeto y el } \\
\text { verbo, género y número y entre el } \\
\text { verbo y los sintagmas. Sin } \\
\text { embargo no utiliza signos de } \\
\text { puntuación. }\end{array}$ \\
\hline $\begin{array}{l}\text { Proceso psicomotóricos } \mathrm{de} \\
\text { coordinación visomotora }\end{array}$ & $\begin{array}{l}\text { Presenta líneas anómalas, en el } \\
\text { primer texto tiene una escritura } \\
\text { bastante recta, pero en el segundo } \\
\text { las líneas se unen. También tiene } \\
\text { un trazo tenso ya que hay } \\
\text { momentos en los que se aprecia } \\
\text { que aprieta mucho el lápiz, o por } \\
\text { ejemplo cuando no sabe escribir } \\
\text { una palabra parece que realiza un } \\
\text { trazo más agresivo. Sin embargo, } \\
\text { no tiene claridad caligráfica, } \\
\text { regularidad de la escritura ni un } \\
\text { tamaño irregular de las letras }\end{array}$ & $\begin{array}{l}\text { No presenta líneas anómalas, } \\
\text { claridad caligráfica ya que cuesta } \\
\text { entender muchas de las palabras } \\
\text { del texto. Muchas de las palabras } \\
\text { del texto están bien escritas, y en } \\
\text { muchas partes parece que está } \\
\text { escribiendo recto y luego se } \\
\text { tuerce otra vez por lo que no hay } \\
\text { regularidad en la escritura. } \\
\text { Tampoco hay tamaños } \\
\text { irregulares de las letras ya que } \\
\text { estas son más o menos aparecen } \\
\text { del mismo tamaño, pero algunas } \\
\text { de ellas resaltan por ser más } \\
\text { grandes. Por último, presenta } \\
\text { trazo tenso y esto se puede } \\
\text { observar como muchas palabras } \\
\text { están escritas de una manera más } \\
\text { "floja", y otras de una manera }\end{array}$ \\
\hline
\end{tabular}




\begin{tabular}{|l|l|l|}
\hline & & $\begin{array}{l}\text { más "fuerte", es decir apretando } \\
\text { más con el lápiz o bolígrafo. }\end{array}$ \\
\hline
\end{tabular}

\section{PROCESOS COMPLEJOS DE CARÁCTER COGNITIVO Y REPRESENTACIONAL:}

En un primer momento (An 6), su texto no presenta coherencia en el orden de contenidos, ni hay uso de conectores, ni espacios entre palabras debido a que el texto está formado por una sola palabra.

Más tarde (An 7), continúa sin presentar coherencia en los contenidos sino que varía pero mejora en lo referente al uso de conectores en el texto y al dejar espacio entre palabras.

Después (An 9), vuelve a caer en los errores de no dejar espacio considerable para que se entienda la diferenciación de las palabras y no presentar ningún conector en el primer texto. Sin embargo, continúa teniendo coherencia en sus ideas.

Por último (An 11), mejora ya que deja espacio entre las palabras, el texto tiene una correcta estructuración del orden de contenido y usa los conectores correctamente.

\section{PROCESOS BÁSICOS DE CARÁCTER LINGÜÍSTICO: LÉXICO}

En principio (An 6) no es capaz de producir un texto, ya que como podemos observar solo es capaz de escribir una palabra y no de expresar sus ideas, lo que se puede observar en el texto es que no respeta los márgenes.

Con el tiempo (An 7) se puede observar que es capaz de empezar a reproducir sus ideas en un texto, pero presenta errores de acentuación, también realiza omisiones de palabras así como también une algunas palabras, y sigue respetando los márgenes del texto.

Seguidamente (An 9) sigue teniendo los mismos errores de acentuación que anteriormente, así como también sigue uniendo palabras, haciendo omisiones y además crea pseusopalabras así como también confunde grafemas, algo que se puede ir observando con la evolución de los textos, porque cada vez es más capaz de producir textos más elaborados.

Finalmente (An 11) sigue presentando problemas de acentuación, sigue creando pseudopalabras y presenta fragmentación en algunas palabras, pero se puede observar como ya no omite palabras, si confunde grafemas, y ya es capaz de explayar sus ideas en un texto.

\section{PROCESOS BÁSICOS DE CARÁCTER LINGÜÍSTICO: SINTAXIS}

En un principio (An 6) el texto que produce no tiene ningún sentido lógico, ya que no es capaz de producir un texto y solo ha escrito una palabra. 
Seguidamente (An 7) el texto que produce sigue sin tener sentido lógico, no existe concordancia, así como tampoco utiliza signos de puntuación, ni puntos, ni comas, lo que hace muy difícil su comprensión.

A continuación (An 9) en la producción de su texto ya presenta un sentido lógico y concordancia en todos los aspectos, pero sigue sin utilizar ni puntos, ni comas, lo que sigue haciendo difícil su comprensión.

Finalmente (An 11) en la producción de su texto presenta una concordancia en todos los aspectos, dicho texto está estructurado perfectamente, y es capaz de explayar sus ideas, aunque sigue sin utilizar signos de puntuación lo que hace difícil su comprensión.

\section{PROCESO PSICOMOTÓRICOS DE COORDINACIÓN VISOMOTORA}

En un inicio (An 6), la palabra escrita se presenta curvada pero al no haber más palabras no se unen las líneas. Del mismo modo, no tiene claridad caligráfica debido a que tanto la "e" como la "a" de “esta" pueden llevar a confusión. Se aprecia que aprieta mucho el lápiz, y 6 que ha repasado la palabra una vez escrita. Además, se muestra un tamaño normal, quizás un poco más grande, pero tampoco excesivo.

Seguidamente (An 7), continúa sin claridad caligráfica ya que algunos casos no se entiende lo que ha escrito, en algunas partes del texto escribe bien las palabras y con clarisas, mientras que en otras no se entiende nada por lo que no presenta regularidad en la escritura y el tamaño de las letras sigue siendo más o menos el mismo excepto en una o dos letras. Por otro lado, ya no presenta un trazo tenso en la escritura, esto se puede observar cómo escribe con un trazo en su mayoría regular. El texto presenta líneas anómalas.

A continuación (An 9), persiste presentando líneas anómalas debido a que en el primer texto hay una escritura bastante recta, pero en el segundo las líneas se unen. Continúa sin tener claridad caligráfica, regularidad de la escritura ni un tamaño irregular de las letras. Vuelve a tener un trazo tenso ya que hay momentos en los que se aprecia que aprieta mucho el lápiz, por ejemplo, cuando no sabe escribir una palabra parece que realiza un trazo más agresivo.

Para finalizar (An 11), mejora ya que no presenta líneas anómalas. Por otro lado, continúa sin presentar claridad caligráfica debido a que cuesta entender muchas de las palabras del texto y en muchas partes parece que está escribiendo recto y luego se tuerce otra vez por lo que tampoco hay regularidad en la escritura. Sigue sin presentar tamaños irregulares de las letras ya que estas son más o menos aparecen del mismo tamaño pero sigue teniendo un trazo tenso y esto se puede observar como muchas palabras están escritas de una manera más "floja”, y otras de una manera más "fuerte”, es decir apretando más. 